\title{
A MUDANÇA DE PARADIGMAS DA CIÊNCIA E A RELAÇÃO COM A EDUCAÇÃO ESCOLAR
}

\author{
Astrogildo Fernandes da Silva Júnior
}

\begin{abstract}
RESUMO
Este artigo tem como objetivo refletir sobre a relação entre o modelo de ciências e a educação escolar. Nesse sentido, algumas questões tornaram-se recorrentes: Existe um diálogo entre modelo de ciências, teoria de aprendizagem e práticas pedagógicas? Como se deu o processo da construção das ciências? Quais as dificuldades, necessidades e possibilidades da educação nesse contexto? Na procura de respostas às referidas inquietações, podem ser consideradas básicas as obras de Morin (2001), O Método 4, e Levi (2007), A inteligência Coletiva. Ao fazer o exercício de refletir sobre a mudança de paradigmas da Ciência e a relação com a educação escolar, foi possível vislumbrar uma "nova escola".
\end{abstract}

Palavras-chave: Educação escolar. Ciência moderna. Crise de paradigmas.

\begin{abstract}
This article has the object to reflect about the relationship between the science model and school education. In this context, some questions are raised: Is there a dialog between science model, knowledge management theory and pedagogical practices? How the process of sciences constructions was performed? Which were the difficulties, necessities and possibilities of education in this context? In search for answers to the cited questions, one can consider Morin (2001) in La Méthode 4 and Levi (2007) in L'intelligence collective. During the reflection concerning the changes of science paradigms and the relationship with school education, it was possible to glimpse a "new school".
\end{abstract}

Keywords: School education. Modern science. Paradigms crisis.

\footnotetext{
* Doutorando em Educação na Universidade Federal de Uberlândia (UFU). Professor titular do Curso de História da Universidade Federal de Uberlândia (UFU-FACIP). E-mail: silvajunior_af@yahoo.com.br
} 
Gosto de ser gente porque, inacabado, sei que sou um ser condicionado, mas consciente do inacabamento, sei que posso ir mais além dele (FREIRE, 1987).

(...) É verdade que, em escala humana, a inteligência é abertura para um exterior, inacabamento perpétuo, esforço para fora e o que não é si mesmo. Aprender é entrar no mundo do outro (...) (LÉVY, 2007).

\section{Introdução}

A educação é um processo de natureza prática e, esse é um motivo que dificulta o estatuto epistemológico de um campo próprio de um saber científico na esfera educacional. Segundo Severino (2006), a educação é uma prática intencionada, tem um caráter prático. Sua existência, sua realidade, sua substancialidade se constituem por essa condição de ser uma ação de intervenção social que constrói os sujeitos humanos. Iniciei este texto com as epígrafes de Paulo Freire e Pierre Lévy, pois considero que estas justificam a importância da educação em um processo que permita construir uma sociedade mais humana, mais justa e democrática. Por um lado, penso que os paradigmas da ciência influenciam a educação, mas, por outro, acredito na possibilidade da educação interferir e transformar paradigmas.

A educação escolar comprometida com a transformação da realidade deve estar antenada com o contexto atual, porém não pode desprezar aspectos relevantes da tradição. Comungo com Arendt (1972), quando afirma que a educação, no sentido amplo da palavra, está entre as atividades mais elementares e necessárias da sociedade humanas. $\mathrm{O}$ ofício do professor é o de ser mediador entre o velho e o novo, desse modo, sua profissão exige um respeito extraordinário pelo passado e uma visão crítica da realidade presente.

Vivemos um tempo de mudanças. Em uma época de instabilidade e de competição internacional. Em um mundo social em que se articulam multiculturalismo, relativismo, fundamentalismos, liberalismo econômico, conservadorismo moral e político. Em um mundo marcado 
pela globalização. Estamos vivendo uma mudança dentro da própria mudança. Segundo Bauman (1999), uma parte integrante dos processos de globalização é a progressiva segregação espacial, a progressiva separação e exclusão. Bauman (2007) qualifica esse contexto como "tempos líquidos", ou seja, a representação do tempo associado a uma época de incertezas e de riscos. É nesse mapa cultural e político que se situa a chamada crise da educação vivenciada de forma aguda e complexa pela sociedade brasileira contemporânea

No presente texto, tenho como objetivo refletir sobre a relação entre o modelo de ciências e a educação escolar. Nesse processo, algumas questões tornaram-se recorrentes: Existe um diálogo entre modelo de ciências, teoria de aprendizagem e práticas pedagógicas? Como se deu o processo da construção das ciências? Quais as dificuldades, necessidades e possibilidades da educação nesse contexto?

$\mathrm{Na}$ procura de respostas às referidas inquietações, considero básicas as obras de Morin (2001) e Levi (2007). A primeira, O Metódo 4, segundo o autor, constitui a introdução mais acessível ao conhecimento do conhecimento e, ao mesmo tempo, ao problema e à necessidade de um pensamento complexo. A segunda, A inteligência coletiva, tem como objetivo contribuir para situar a atual evolução em uma perspectiva antropológica e para forjar uma visão positiva que poderia ajudar as políticas, as decisões e as práticas a se orientar no labirinto de um futuro ciberespaço.

$\mathrm{O}$ texto, por questões didáticas, foi organizado em três partes. $\mathrm{Na}$ primeira, busquei compreender a construção da ciência moderna e a sua relação com a educação. Na segunda, caracterizei o contexto marcado pela globalização e apresentei questionamentos sobre a ciência e a relação com o processo educativo e, por fim, teci algumas considerações.

\section{A construção da ciência moderna e a sua relação com a educação}

Segundo Chalmers (1981), Francis Bacon foi um dos primeiros a articular o que é o método da ciência moderna. Propôs que a meta da ciência é o melhoramento da vida do homem na terra e, para isso, deveria coletar fatos com observação organizada e derivar, a partir daí, novas 
teorias. Bacon formulou a teoria da indução, que serve para descrever minuciosamente os cuidados, técnicas e procedimentos para a investigação dos processos naturais. A máxima baconiana é: "saber é poder". Assim, para dominar a natureza, é preciso conhecer as leis da natureza por meios comprovados por intermédio de experimentos.

Descartes, também considerado com um dos pilares da ciência moderna, vai inequivocadamente, das ideias para as coisas, e não das coisas para as ideias, e estabelece a prioridade da metafísica como fundamento último da ciência. Para Descartes, segundo Santos (2001, p. 63), "as ideias que presidem a observação e a experimentação são as ideias claras e simples a partir das quais se pode ascender a um conhecimento mais profundo e rigoroso da natureza". Essas ideias são as ideias matemáticas. A matemática forneceu para ciência moderna o instrumento de análise, a lógica da investigação e o modelo de representação da própria estrutura da matéria.

O método cartesiano consiste de quatro regras básicas, que, segundo Descartes, são capazes de conduzir o espírito à verdade. Em primeiro lugar, a evidência, o objeto deve ser exposto com clareza; em segundo lugar, a decomposição, é preciso dividir em tantas partes, em quantas forem necessárias; em terceiro, a ordenação, é fundamental partir dos problemas mais simples para os mais complexos; por fim, a revisão, é imperativo fazer as verificações para certificar-se de que nada esteja errado.

O modelo explicativo filosófico cartesiano do mundo, como afirmei anteriormente, ampara-se na matemática, vem a se constituir na medida e na forma do Ser. A valorização da matemática decorre de dois aspectos que a caracterizam. Em primeiro lugar, da idealidade pura de seus objetos, que não se confundem com as coisas percebidas subjetivamente por nós, são universais e necessárias. Em segundo lugar, devido à precisão e ao rigor dos princípios e demonstrações matemáticas, que seguem regras universais e necessárias, de tal modo que a demonstração de um teorema seja a mesma em qualquer época e lugar, e a solução de um problema se faça pelos mesmos procedimentos em toda época e lugar.

O primado da individualidade tornou-se o centro de interesse dos valores e do conhecimento. Os desdobramentos da ideia filosóficocartesiano, baseados no princípio das ideias claras e precisas, e a proposição empírica dos fatos e das coisas, ou seja, as "ideias" e as constatações 
empíricas consolidam o paradigma da ciência moderna. Podemos, a partir de então, falar de um modelo global, isto é, ocidental, de racionalidade científica que, segundo Santos (2001), admite variedade interna, mas se defende, ostensivamente, de duas formas de conhecimento não científico: o senso comum e as chamadas humanidades.

De acordo com Morin (2007), no final do segundo milênio, o mundo científico considerava que as ciências repousavam sobre três pilares de certeza: 1) o primeiro era a ordem, a regularidade, a constância e, sobretudo, o determinismo absoluto; 2) o segundo pilar era a separabilidade, ou seja, para conhecer um objeto, basta isolá-lo conceitual ou experimentalmente, extraindo-o de seu meio de origem para examiná-lo num meio artificial; 3) o terceiro pilar era o valor da prova absoluta fornecida pela indução e pela dedução e pelos princípios aristotélicos que estabelecem a unicidade da identidade e a recusa da contradição. O rigor científico afere-se pelo rigor das medições, o que não é quantificável é cientificamente irrelevante. Outro aspecto do método científico assenta-se na redução da complexidade; conhecer significa dividir e classificar para, depois, determinar relações sistemáticas entre o que se separou.

De acordo com Santos (2001), a natureza teórica do conhecimento científico decorreu dos pressupostos epistemológicos e das regras metodológicas. É um conhecimento causal, que aspira à formulação de leis, à luz de regularidades observadas, com vista a prever o comportamento futuro dos fenômenos. Tem como pressuposto metateórico a ideia de ordem e de estabilidade do mundo. É a ideia de um mundo máquina. Conforme Santos (2001), o determinismo mecanicista é o horizonte certo de uma forma de conhecimento que se pretende utilitário e funcional, reconhecido menos pela capacidade de compreender profundamente o real do que pela capacidade de dominar.

Que modelo de educação escolar se consolidou a partir do paradigma da ciência moderna? Que tipo de conhecimento passou a ser incentivado? Qual passou a ser rechaçado? Antes de continuar essa reflexão, destaco um alerta de Morin:

o conhecimento está ligado, por todos os lados, à estrutura da cultura, à organização social, à práxis histórica. Ele não é apenas condicionado, 
determinado e produzido, mas é também condicionante, determinante e produtor (o que demonstra de maneira evidente a aventura do conhecimento científico). É sempre e por toda a parte, o conhecimento transita pelos espíritos individuais, que dispõem de autonomia potencial, a qual pode, em certas condições, atualizar-se e tornar-se um pensamento pessoal (MORIN, 2001, p. 27).

Por um lado, é possível vislumbrar a possibilidade de romper com o que está posto, por outro, não podemos ignorar as dificuldades impostas. Morin (2001) alerta-nos sobre os determinismos culturais: imprinting e normalização. Consoante o autor, "a determinação cultural impõese, não somente do exterior ao espírito individual (normalização), mas, sobretudo, interiormente (imprinting a partir dos princípios organizadores do conhecimento, postulados, axiomas, modelos explicativos, doutrinas)" (MORIN, 2007, p. 93). É um determinismo, ao mesmo tempo, de norma/ proibição e de reprodução, que nos deixa prisioneiros das condições socioculturais e históricas.

Dessa forma, podemos ter a clareza de que somos seres condicionados, mas não determinados. Portanto, podemos pensar em transformações. Mas, primeiramente, proponho refletir sobre como o processo científico da modernidade ${ }^{1}$ foi transportado para o campo da Educação, encontrando aí terreno fértil. A escola passou a organizar o que deve ser ensinado em compartimentos estanques. $\mathrm{O}$ argumento pedagógico subjacente é que se torna mais fácil, também para os alunos, o acesso e a compreensão do conteúdo curricular, uma vez que se opera com aquele mecanismo lógico cartesiano fundado na divisão e disciplinarização.

É possível definir a disciplinarização como a delimitação de campos específicos para cada forma de abordar um determinado aspecto da realidade, cada um deles dando origem a uma disciplina específica e independente. A constituição da ciência moderna dá-se no contexto de uma

\footnotetext{
1 É importante destacar que modernidade também se caracteriza por uma ruptura com a tradição que leva à busca no sujeito pensante, de um novo ponto de partida alternativo para a construção e a justificação do conhecimento. O conhecimento científico moderno surgiu no século XVIII, combatendo as narrativas não cientificas pré-modernas consideradas como ignorância, preconceito, barbárie, superstição e ideologia, mas se tornou a grande narrativa dominante até o final da Segunda Grande Guerra.
} 
racionalidade operativa, isto é, que se realiza pela divisão do campo em subcampos menores, portanto, a disciplinarização deve-se a ela.

De acordo com Santomé (1998), a disciplina funciona como uma forma de organizar e delimitar um território de trabalho dentro de um determinado ângulo de visão. Dessa maneira, cada disciplina oferece uma imagem da realidade particular sob o ângulo observado. Embora os conhecimentos de cada disciplina sejam pré-estabelecidos, não são imutáveis, estão em constante transformação e evolução em consonância com a história e a força que esta exerce sobre os homens e as mulheres que constroem e reconstroem os conhecimentos.

As disciplinas manifestam-se politicamente, pois possuem organizações, limites e estruturas; possuem ainda grupos de pessoas que as defendem e divulguem. Elas, ao longo do tempo, impõem determinadas formas de pensar, contribuindo para marginalizar e silenciar muitas dimensões da realidade. Nesse sentido, quanto mais familiarizada uma pessoa estiver com determinada teoria e seu correspondente modo de pensar, mais difícil ser-lhe-á adotar uma teoria rival que implique uma maneira diferente de pensar. Em geral, a posse de conhecimentos proporciona asas em certo aspecto, cortando-as em outro.

As instituições universitárias exercem influência decisiva na formação das disciplinas, na busca de objetos de estudo, na elaboração e formalização dos conceitos obtidos. Surgem, assim, diversas disciplinas científicas, apresentando-se como conjuntos ordenados de conceitos, problemas, métodos e técnicas que pretendem organizar nosso pensamento, possibilitando a análise e a interação com a realidade. Porém um mesmo objeto de estudo possibilitará a existência de vários campos científicos que mantém uma desconexão entre si, dificultando a compreensão real e completa dos fenômenos dos quais se ocupam.

A construção do conhecimento disciplinar formaliza-se com a utilização de seleção de dados significativos ou não. Esta seleção está controlada por paradigmas que organizam o pensamento e a visão da ciência e da realidade, contribuindo para uma compartimentação em especialidades, que, dessa forma fragmentada, dificilmente oferece um significado verdadeiro da totalidade. 
Nesse contexto, aos alunos está negada qualquer possibilidade de poder intervir nos processos educacionais, seus papéis se limitam à obediência e à submissão à autoridade. A reflexão crítica é negada, pois os conteúdos se apresentam desconexos, separados, descontextualizados do mundo em que vivem. A escola elaborou o modo de educar o homem enfocando seus aspectos lógico-formais, de memorização, mantendo a ritualística linear, com base na percepção equivocada de transmissão de conhecimento.

A base para a formulação das práticas curriculares de ensino e de aprendizagem absolutizaram apenas a razão e a experimentação, omitindo processos característicos da humanidade, como a emoção, as suas subjetividades, ou seja, operando por seleção de dados significativos e rejeição de dados não significativos. Destacaram-se trabalhos planejados com base em um enfoque centralizado, sem considerar o contexto, sem envolvimento por parte dos alunos, voltado para o atendimento de uma massa amorfa, homogeneizada, desconsiderando as diferenças.

O cotidiano das salas de aula, para a maioria dos professores, é caracterizado pela forma de interpretar o mundo e construir o conhecimento mediado pela visão da física clássica. Esta compreende a realidade como sendo estruturada, estável, e a maioria dos acontecimentos, previsível, predeterminada, e a racionalidade como o estado da mente mais utilizável para a construção do conhecimento técnico-científico. Nas práticas educativas prevalecem a homogeneidade, a objetividade e a uniformização. Nesse paradigma, existe apenas um único caminho, uma única metodologia, uma única maneira de realizar algo. O professor é quem fala e o aluno escuta e copia para reproduzir na prova o que foi dito.

Comungo com Santos (2001), ao afirmar que há indícios de que o modelo de racionalidade científica atravessa uma profunda crise. Essa crise é refletida na educação escolar. As pesquisas acadêmicas, as mídias televisivas e escritas confirmam o fracasso escolar. É importante investigar o que se denomina de "fracasso escolar", a culpa é dos alunos? Dos professores? Ou esse paradigma não responde às necessidades do atual contexto? Santos (2001) adverte que no lugar da eternidade temos a história; a imprevisibilidade substitui o determinismo; o mecanicismo perde lugar para a interpretação; a espontaneidade ao invés auto-organização, 
da reversibilidade; a irreversibilidade e a evolução; ao invés da ordem, a desordem; ao invés da necessidade, a criatividade e o acidente. Para buscar respostas, na continuação desse texto, reflito sobre a crise de paradigmas e a relação com a educação escolar.

\section{A crise de paradigmas e a relação com o processo educativo}

Considero Thomas Kuhn (1987) uma referência fundamental para refletirmos sobre a noção de paradigma. $\mathrm{O}$ autor enfoca o desenvolvimento da ciência a partir das realizações de uma determinada comunidade científica inserida em um contexto histórico, que ele denomina tradição ou matriz disciplinar. Estas tradições e o fato de os cientistas se ligarem a elas de forma incondicional determinaram o desenvolvimento das ciências da natureza. Kuhn (1987) denomina tais tradições ou matrizes disciplinares de paradigmas. Dessa forma, o conceito de paradigma, devido à sua abrangência e generalidade, baseia-se em visões de mundo, de natureza e de ciência alimentadas pelos cientistas. Ao enfatizar o momento de subjetividade no fazer ciência, destrói a ideia de objetividade científica sustentada pela tendência analítica² .

Kuhn (1989) resgata elementos constitutivos da metafísica como concepções de mundo, de natureza, de homem, enfim, valores pertencentes ao imaginário daqueles que fazem ciência e que são indissociáveis de trabalho científico. O primado da subjetividade em oposição à objetividade científica e o papel da metafísica, inerente ao fazer ciências, são traços característicos da teoria kuhniana.

A história da humanidade pode ser caracterizada por revoluções científicas, desencadeadas por um número crescente de anomalias que ultrapassam a capacidade de resolução de problemas de um paradigma. Quando as anomalias não são contornadas, instala-se um período de crise. Kuhn (1987) define crise como um estado de insegurança profissional

\footnotetext{
2 Segundo Silva (1998), a pretensão de fundamento último proposta pela filosofia da ciência analítica pode ser constatada na forma pela qual o seu discurso visa demarcar o que é e o que não é ciência. O conceito de base empírica ilustra esta afirmação: ciência é todo conhecimento mensurável, experimental, garantido pela observação. Todo o restante não ciência ou metafísica.
} 
e emocional, caracterizado por um sentimento de impotência face às circunstâncias.

O atual contexto é marcado pela globalização, que segundo Ortiz (2007), se aplica à realidade técnica e econômica e pela mundialização, que se adapta melhor ao universo da cultura. Para o autor, a situação de globalização caracteriza-se pela emergência do novo e pela redefinição do "velho". Ortiz afirma que:

Ambos se encontram inseridos no mesmo contexto; nele, diversas temporalidades se entrecruzam. Não é, pois, necessário opor tradição a modernidade, local a global. Importa qualificar de que tipo de tradição estamos falando (a tradição da modernidade ou as tradições dos inúmeros grupos indígenas) e pensa-las nas formas de sua articulação à modernidade-mundo. Da mesma maneira, o local e o nacional não devem ser considerados como dimensões em vias de desaparecimento; trata-se de entender como esses níveis são redefinidos. Na situação de globalização co-existe, portanto, um conjunto diferenciado de unidades sociais: nações, regiões, tradições e civilizações. A diversidade é parte integrante dessa totalidade (ORTIZ, 2007, p. 11).

Nessas circunstâncias, como pontuei anteriormente, o paradigma da ciência moderna não consegue responder aos desafios. A teoria da complexidade defendida por Morin (2005), dentre outros autores, aponta alguns caminhos para repensar a educação neste novo século. Essa teoria ampara-se nos seguintes conceitos norteadores: auto-organização, autoconsciência, autopoesis, conectividade, correlação, dialogicidade, diversidade, emergência, fluxo, paradoxo, aderência, potencialidade, ressonância, rizoma e virtualidade.

Para compreender alguns desses conceitos, é importante refletir sobre um dos fundamentos da teoria da complexidade, o princípio da incerteza. Este demonstra que é impossível separar o sujeito do objeto, pois ambos só existem a partir de suas relações, correlações e conecções, o que deu origem à intersubjetividade, que nega a objetividade como critério da cientificidade. Isso denota que sujeito e objetos não desaparecem, mas ambos precisam estar relacionados para serem compreendidos, precisam 
ser contextualizados. Segundo Araújo (2007), o princípio da incerteza combateu a noção de causa/efeito da ciência clássica e questionou também a estabilidade do mundo, a determinação, a previsibilidade dos fenômenos, o controle dos processos e a causalidade linear.

Por sua vez, Morin (2001) destaca três princípios para refletir sobre a complexidade: o dialógico, o recursivo e o hologramático. O princípio dialógico remete-nos aos ensinamentos de Paulo Freire, que critica a causalidade linear, no conceito da educação bancária, na qual os alunos são vistos como uma tabula rasa e o professor o único que detém o saber. Cabe ao professor ensinar e ao aluno aprender. Morin argumenta que:

Quando o intercâmbio dialógico deixa-se ampliar com ideias e conhecimentos vindos de outras culturas, constituem-se então possibilidades de hibridização e de síntese de teorias, filosofias e visões de mundo. Esse comércio ampliado favorece o desenvolvimento do espírito crítico, o qual, naturalmente, originará diversas correntes, umas, cada vez, mais relativistas e céticas, outras, ainda, cada vez mais atentadas ás observações empíricas. Constituem-se e instituem-se, então, algumas das condições placentárias do conhecimento científico (MORIN, 2001, p. 46).

Conforme o autor, é preciso juntar princípios, ideias e noções que parecem opor-se uns a outros. O princípio dialógico é necessário para afrontar realidades profundas, que, exatamente, unem verdades aparentemente contraditórias, ou seja, associar dois termos ao mesmo tempo complementares e antagônicos. A dialógica defende a capacidade que uma ação tem de associar-se a outra de maneira complementar, concorrente ou antagônica.

O segundo princípio sobre o qual me proponho refletir é o da recursão. Um processo recursivo é aquele em que os produtos e os efeitos são, ao mesmo tempo, causas e produtores do que os produz. É possível perceber que o circuito recursivo rompe com a causalidade linear, com a ideia de produto/produtor, de estrutura/superestrutura. No caso da educação escolar, as recentes pesquisas mostram que o aluno é influenciado pelo meio (professores e colegas), mas também influencia, ou seja, o sistema 
educacional produz determinado tipo de aprendiz, que, por sua vez, como sujeito aprendente, também influencia pelas interações recorrentes. A análise desse princípio permite perceber que tudo que é produzido retorna sobre aquilo que o produziu, de forma cíclica, isso se dá em função do processo de auto-organização, em que o sujeito, no caso o aluno, é autoorganizador e autoprodutor.

O terceiro princípio que caracteriza a teoria da complexidade é o hologramático. Segundo Morin (2007), esse princípio refere-se ao ponto do holograma que contém a quase totalidade da informação da figura representada. A ideia do holograma vai além do reducionismo, que só vê as partes e do holismo, que só vê o todo. Tal como o holograma, a teoria científica é composta de pontos, cada um contém toda a informação do conjunto que ele apresenta. Nesse sentido, a sociedade, entendida em seu todo, também se encontra presente em nosso próprio interior, pois somos portadores de sua linguagem e de sua cultura. Assim, Morin comenta que:

nas sociedades complexas que comportam pluralismos e antagonismos (sociais, políticos e culturais), esses antagonismos podem entrar em confronto em um mesmo espírito, aí provocando conflito interior, double-bind, crise, investigação. Assim, o que está presente no espírito individual não é somente o Todo como subjugação, mas, também, eventualmente, o Todo como complexidade (MORIN, 2001, p. 102).

Esse princípio é caracterizado pela articulação dos pares binários: parte-todo, simples-complexo, local-global, unidade-diversidade, particular-universal. É possível ressaltar o paradoxo do uno e do múltiplo. A visão holográfica propicia o movimento de religação ao conjunto desmontado, à totalidade fragmentada.

Uma análise relevante sobre o atual contexto, na qual se destaca a importância de "quebrar" paradigmas, é elaborada por Pierre Lévy. Em sua obra, $A$ inteligência coletiva, o autor afirma que as últimas décadas do século XX foram marcadas pela rapidez do processo tecnológico. As novas técnicas de comunicação por mundos virtuais põem em novas bases os problemas do laço social, que reside na economia do humano. Segundo Lévy (2007), a hominização, o processo de surgimento do gênero humano, 
encontra-se em aceleração brutal. É um momento que possibilita pensar coletivamente nossa aventura e melhor podermos influenciá-la.

De acordo com Pierre Lévy, o ciberespaço pode ser um ambiente capaz de consolidar a "tecnodemocracia" ou "democracia eletrônica", ou seja, uma nova configuração política em que as novas tecnologias comunicacionais, em rede, viabilizariam o desenvolvimento da inteligência coletiva que, conforme Lévy é:

uma inteligência distribuída por toda parte, incessantemente valorizada, coordenada em tempo real, que resulta em uma mobilização efetiva das competências. Acrescentemos à nossa definição este complemento indispensável: a base e o objetivo da inteligência coletiva são o reconhecimento e o enriquecimento mútuos das pessoas, e não o culto de comunidades fetichizadas ou hipostasiadas (LÉVY, 2007, p. 28-29, grifos do autor).

Para melhor compreender o conceito de inteligência coletiva, o autor retoma algumas características fundamentais: uma inteligência distribuída por toda parte, ou seja, ninguém sabe tudo, todos sabem alguma coisa, todo o saber está na humanidade; uma inteligência incessantemente valorizada deve-se estimar todas as inteligências e não relegá-las à segundo plano; a coordenação das inteligências em tempo real, o autor propõe permitir aos membros de coletivos malsituados interagir em uma paisagem móvel de significações; atingir uma mobilização efetiva das competências, para isso, é imperativo reconhecer a diversidade. Esse projeto convoca um novo humanismo, que valoriza o pensar juntos (LÉVY, 2007, p. 29-30).

Como pensar a educação escolar a partir desses referenciais? Acredito ser urgente a necessidade de corrigir possíveis erros e a esterilidade acarretada por uma ciência excessivamente compartimentada e sem comunicação interdisciplinar. A necessidade de superarmos os currículos estanques existentes em nossas escolas pressupõe uma integração das disciplinas. De acordo com Fazenda, esta deve ser pensada tanto em relação aos conteúdos e métodos, como conhecimentos parciais, específicos, tendo em vista um conhecimento global, pois segundo a autora, 
um projeto interdisciplinar de trabalho ou de ensino consegue captar a profundidade das relações conscientes entre as pessoas e entre as pessoas e coisas. Nesse sentido, precisa ser um projeto que não se oriente apenas para o produzir, mas que surja espontaneamente, no suceder diário da vida, de um ato de vontade. Nesse sentido, ele nunca poderá ser imposto, mas deverá surgir de uma proposição, de um ato de vontade frente a um projeto que procura conhecer melhor. No projeto interdisciplinar, não se ensina, nem se aprende: vive-se, exerce-se (FAZENDA, 1991, p. 17).

Dessa forma, Fonseca (2005) argumenta que a interdisciplinaridade não é apenas uma fusão ou justaposição, mas uma "interpenetração" de conceitos, dados e metodologias, pressupondo, assim, uma integração entre os conteúdos e as metodologias de disciplinas diferentes, que se propõem a trabalhar conjuntamente determinados temas.

Para além da interdisciplinaridade, proponho refletir sobre a transversalidade. Este termo foi desenvolvido, segundo Gallo (2008), por Félix Guattari, para tratar das relações entre pacientes e terapeutas, substituindo a relação de transferência proposta por Freud. A transferência é hierárquica e unitária, pois ocorre apenas entre o terapeuta e seu paciente de forma individualizada. Preocupado em desenvolver uma terapêutica coletiva e não hierárquica, Gattari propôs a transversalidade como forma de atravessar as relações entre as pessoas.

$\mathrm{Na}$ educação, fala-se em saberes transversais, o que significa atravessar diferentes campos de conhecimento, sem identificar-se necessariamente com apenas um deles. É baseado no modelo rizomático ${ }^{3}$,

\footnotetext{
3 De acordo com Deleuze e Guattari (1995), o paradigma rizomático é regido por seis princípios básicos: princípio da conexão - qualquer ponto de um rizoma pode ser/estar conectado a qualquer outro; no paradigma arbóreo, as relações entre pontos precisam ser sempre mediatizadas obedecendo a uma determinada hierarquia e seguindo uma ordem intrínseca. b) Princípio de heterogeneidade - dado que qualquer conexão é possível, o rizoma rege-se pela heterogeneidade; enquanto que na árvore a hierarquia das relações leva a uma homogeneização das mesmas, no rizoma isso não acontece. c) Princípio de multiplicidade - O rizoma é sempre multiplicidade que não pode ser reduzida à unidade; uma árvore é uma multiplicidade de elementos que pode ser "reduzida" ao ser completo e único árvore. d) Princípio da ruptura a-significante - o rizoma não pressupõe qualquer processo de significação, de hierarquização. Embora seja estratificado por linha, sendo,
} 
que implica o entrecruzamento das linhas, pelo qual é possível perceber as inter-relações intrínsecas que compõem os híbridos, como elementos de nossa realidade. A transversalidade integra as várias áreas do saber, senão em sua totalidade, pelo menos, de forma muito mais abrangente, possibilitando conexões inimagináveis.

O acesso transversal significaria o fim da compartimentalização, pois as "gavetas" seriam abertas, reconhecendo a multiplicidade das áreas do conhecimento, que trata-se de possibilitar todo e qualquer trânsito entre elas. Uma efetiva autonomia do discente pode ser assim instaurada, mas seria praticamente impossível exercer sobre ele os mecanismos de controle, posto que cada um poderia construir, com sua experiência de aprendizagem, um mapa, em muito diferente dos demais.

Corroboro com Freire (1981) ao asseverar que em todo homem existe um ímpeto criador. $\mathrm{O}$ ímpeto de criar nasce da inconclusão do homem. A educação é mais autêntica quanto mais desenvolve esse ímpeto ontológico de criar. Deve ser desinibidora e não restritiva. É necessário darmos oportunidade para que os educandos sejam eles mesmos. Caso contrário, domesticamos, o que denota a negação da educação. Um educador que restringe os educandos a um plano pessoal impede-os de criar. Muitos consideram que o aluno deve repetir o que o professor ensina na classe. Isto significa tomar o sujeito como instrumento.

O desenvolvimento de uma consciência crítica, que é possível por meio da transversalidade no currículo, permite ao homem transformar a realidade, e isso se faz cada vez mais urgente. Assim, à medida que os homens, dentro de uma sociedade, vão respondendo aos desafios do mundo, vão temporalizando os espaços geográficos e vão fazendo história pela própria atividade criadora. Uma educação que pretendesse adaptar o homem estaria matando suas possibilidades de ação, transformando-o em

assim, territorializado, organizado etc., está sempre sujeito a linhas de fuga. e) Princípio de cartografia - O rizoma pode ser mapeado, cartografado e tal cartografia nos mostra que ele possui entradas múltiplas, isto é, o rizoma pode ser acessado de infinitos pontos e pode daí remeter a quaisquer outros em seu território. f) Princípio de decalcomania - Os mapas podem, no entanto, ser copiados, reproduzidos, colocar uma cópia sobre o mapa nem sempre garante, uma sobreposição perfeita. O inverso é a novidade: colocar o mapa sobre as cópias, os rizomas sobre as árvores, possibilitando o surgimento de novos territórios, novas multiplicidades. 
abelha, executando o trabalho mecanicamente. A educação deve estimular a opção e afirmar o homem como homem. Adaptar é acomodar, não transformar.

A educação do século XXI e para o século XXI não deve se prender aos moldes da educação bancária, em que o educando recebe passivamente os conhecimentos, tornando-se um depósito do educador. Educa-se para arquivar o que se deposita. O curioso é que o próprio homem é que se torna arquivado, perdendo, assim, seu poder de criar, fazendo-se menos homem, tornando-se apenas uma peça. O destino do homem deve ser criar, recriar e transformar o mundo, sendo o sujeito social atuante.

Constitui-se tarefa humana a permanente mudança da realidade para a libertação dos homens. O exercício do diálogo, do multílogo no espaço escolar, apresenta-se como uma possibilidade de retirar o véu, de compreendermos o mundo em que vivemos e assim buscarmos alternativas para transformação. Uma escola que se fundamenta em clima de parceria e companheirismo entre todos os envolvidos, onde acontecerá debates, discussões metodológicas, conceituais e ideológicas, está mais próxima de formar um coletivo inteligente.

\section{Considerações finais}

Ao fazer o exercício de refletir sobre a mudança de paradigmas da ciência e a relação com a educação escolar, foi-me possível vislumbrar uma "nova escola". Defendo a necessidade de ousar experimentar, sonho com uma sociedade mais justa, mais humana, na qual o coletivo possa chegar em primeiro lugar, todos ao mesmo tempo. Concordo com Gallo (2008), quando afirma que não podemos perder de nosso horizonte, que a utopia que nos guia é algo bem maior, a construção de uma concepção de saber que vislumbre a multiplicidade sem a fragmentação; uma escola na qual as crianças possam aprender sobre o mundo em que vivem, um mundo múltiplo e cheio de surpresas, e possam dominar as diferentes ferramentas que permitam seu acesso aos saberes possibilitados por esse mundo, além de aprender a relacionar-se com os outros e com o mundo em liberdade.

$\mathrm{O}$ que podemos fazer pode parecer pouco, mas a pequena ação transformadora no nosso espaço escolar, em que somos autônomos, fará 
uma grande diferença, o que não devemos é continuar reproduzindo a mesmice. Gallo (2008) propõe a educação menor. Para o autor, a aprendizagem é algo que escapa, que foge ao controle, dessa forma, resistir é sempre possível. Desterritorializar os princípios, as normas da educação maior gera possibilidades de aprendizado. A educação menor age nas brechas, nas fissuras e faz emergir caminhos que escapem a qualquer controle. É rizomática, viabiliza conexões sempre novas. Adquire um valor de coletivo. É uma aposta nas multiplicidades, que rizomaticamente se conectam e interconectam, gerando novas multiplicidades.

Guido (2007) fomenta a compreensão do conceito da educação negativa. Segundo o autor, quando se insiste no mote Educação e Cidadania, é porque a sociedade ainda carece desses fatores vitais, portanto, o pensamento do presente confirma a ausência da verdadeira educação e da autêntica cidadania. Daí, a necessidade de um aprendizado negativo, que se constitui a partir da ação histórica compreendida por meio do processo dialético. O que predominou no processo da educação científica, ao longo da modernidade, foi o individualismo. $\mathrm{O}$ autor sugere a coletividade. Defende a democracia em tempo real. Aproxima-nos do que Lévy (2007) nos ensina: 1) escutar os outros coralistas; 2) cantar de modo diferenciado; 3) encontrar uma coexistência harmônica entre sua própria voz e a dos outros, ou seja, melhorar o efeito do conjunto.

Ao escrever este texto, tive o intuito de estimular uma reflexão e um debate, rompendo, acima de tudo, com minhas próprias amarras. Para as condições atuais em que se encontra a educação, devemos nos preocupar, ao menos, com a minimização das aparências da compartimentalização. Começaríamos mostrando, em nossas aulas, que os conteúdos que ensinamos não são isolados, mas se relacionam de algum modo com tudo o mais que se aprende na escola.

De nossa criatividade e de nossa ação política e capacidade de influência é que dependerá o delineamento de um processo educativo, ou teremos uma sociedade em que o controle será exercido de forma diluída e mais intensa, em que teremos apenas ilusão de autonomia, ou uma sociedade em que a autonomia seja um fato, possibilitando uma realidade mais solidária e mais democrática. Defendo a proposição de que a escola não muda o mundo, mas a escola muda o homem e o homem pode mudar 
o mundo. Sendo assim, devemos pensar que a educação pode mudar paradigmas. Esse é o grande desafio!

Para finalizar, gostaria de dividir uma reflexão. Já me disseram que a educação é uma utopia. Questiono: O que é a utopia? Uma utopia é conseguir dar 10 passos em direção ao horizonte e perceber que o horizonte se afastou 10 passos. Novamente questiono: De que adianta a utopia? Fazme caminhar! É assim que me sinto, com a esperança de contribuir, com um forte desejo de buscar mais, conhecer e participar do debate acerca da relação entre os paradigmas da ciência com a educação, debate este que é teórico, pedagógico e, sobretudo, político.

\section{Referências}

ARAÚJO, Maristela Midlej Silva. O pensamento complexo: desafios emergentes para a educação on-line. Revista Brasileira de Educação. Rio de Janeiro, v. 12, n. 36, p. 515-529, set./dez. 2007.

ARENDT, Hanna. Entre o passado e o futuro. São Paulo: Perspectiva, 1972.

BAUMAN, Zygmunt. Globalização: as consequências humanas. Tradução de Marcus Penchel. Rio de Janeiro: Jorge Zahar, 1999.

. Tempos Líquidos. Tradução de Carlos Alberto Medeiros. Rio de Janeiro: Jorge Zahar, 2007.

CHALMERS, Alan. O que é ciência afinal? Tradução de Raul Fiker. Brasília: Editora Brasiliense, 1981.

DELEUZE, Guiles; GUATTARI, Félix. Mil Platôs: capitalismo e esquizofrenia, v. 1. Tradução de Aurélio Guerra Neto e Célia Pinto Costa. São Paulo: 34, 1995.

FAZENDA, Ivani C. Arantes. Interdisciplinaridade. História, teoria e pesquisa - Campinas: Papirus, 1994. (Coleção Magistério: Formação e Trabalho Pedagógico)

FONSECA, Selva Guimarães. Didática e prática de ensino de História. Campinas, Papirus, 2005.

FREIRE, Paulo. Pedagogia do Oprimido, 17. ed. Rio de Janeiro: Paz e Terra, 1987. 
GALLO, Silvio. Deleuze \& a Educação. 2. ed., Belo Horizonte: Autêntica, 2008.

GUIDO, Humberto. Filosofia da Educação: entre o anti-moderno e o ultramoderno. In: HENZ, Celso Ilgo; ROSSATO, Ricardo (Org.). Educação humanizadora na sociedade globalizada. Santa Maria: Biblos, 2007.

KUHN, Thomas. A estrutura das revoluções cientificas. Tradução de Beatriz Vianna Pereira; Nelson Boeira. São Paulo: Perspectiva, 1987.

LÉVY, Pierre. A inteligência coletiva. Tradução de Luiz Paulo Rouane. 5. ed. São Paulo: Edição Loyola, 2007.

MORIN, Edgar. O Método. Tradução de Juremir Machado da Silva. Porto Alegre: Sulina, 2001.

. Educação e complexidade: os sete saberes e outros ensaios. Maria da Conceição de Almeida, Edgard de Assis Carvalho, (Org.). 4. ed. São Paulo: Cortez, 2007.

ORTIZ, Renato. Anotações sobre o universal e a diversidade. Revista Brasileira de Educação, Rio de Janeiro, v, 12, n. 34, p. 7-16, jan./abr. 2007. SANTOMÉ, Jurjo Torres. Globalização e interdisciplinaridade: o currículo integrado. Tradução de Cláudia Schilling. Porto Alegre: Artes Médicas Sul Ltda, 1998.

SANTOS, B. de. S. Da ciência moderna ao novo senso comum. In:

A crítica da razão indolente. Contra o desperdício da experiência. v. 1, 3. ed. São Paulo. Cortez, 2001. p. 55-117.

SEVERINO, Antônio Joaquim. Questões epistemológicas da pesquisa sobre a prática docente. Educação e Linguagem, São Bernardo do Campo, Ano 9, n. 14, p. 34-45, jul./dez. 2006.

SILVA, Rafael Cordeiro. A teoria kuhniana da ciência: um discurso de homenagem. Revista Educação \& Filosofia. Uberlândia, v. 12, n. 24, p. 255-272, jul./dez. 1998.

Data de registro: $13 / 08 / 2010$ Data de aceite: $15 / 12 / 2010$ 
